\title{
Modeling of optimized cascade of quantum cascade detector operating in far infrared range
}

\author{
Seti Ju. O., Tkach M. V., Vereshko E. Ju., Voitsekhivska O. M. \\ Yuriy Fedkovych Chernivtsi National University, \\ 2 Kotsyubynsky Str., 58012, Chernivtsi, Ukraine
}

(Received 23 March 2020; Accepted 11 May 2020)

\begin{abstract}
Using the theory for electron energy spectrum and oscillator strengths of inter-subband quantum transitions, developed in the model of position-dependent effective mass and rectangular potentials, the geometrical design for the compact cascade of a quantum cascade detector (with a two-well active region) operating in far infrared range is proposed. The extractor of the cascade is optimized in such a way that the energy steps of its phonon ladder resonate with optical phonon energy, providing effective phonon-assisted tunneling of electrons between the active regions of cascades. It is shown that increasing thickness of the barrier between the wells of active region, causes the broadening of detector absorption band due to the bigger distance between energy levels in anti-crossing.
\end{abstract}

Keywords: nanosystem, quantum cascade detector, energy spectrum, phonon-assisted tunneling.

2010 MSC: $81-10,81$ V19, 92F99

DOI: $10.23939 / \mathrm{mmc} 2020.01 .186$

\section{Introduction}

The infrared photodetectors have been intensively investigated during the last twenty years. These devices are functioning due to the transitions between quantum electron bands in the nano-size semiconductor quasi-two-dimensional layers of heterostructures. Their operating frequencies are determined by composition and sizes of the layers, from which the active regions consist. Therefore, different methods of band engineering demonstrate detectors of different design [1-4], which operate in wide range of infrared (IR) frequencies: from near- till far-IR.

With respect to the used scheme of electronic current through the active elements, IR photodetectors are of two types: quantum well infrared photodetectors (QWIP) $[4,5]$ and quantum cascade detectors (QCD) $[2,6]$.

The main operating element of typical QWIP [7] contains either isotropic or anisotropic superlattice with the same quantum wells, where an electron, absorbing photon, transits from the ground into the excited state. In isotropic QWIPs [8,9] of mid- and far-IR range, the electric field is used to provide the guided photocurrent. As a result, the dark current and noises appear, essentially increasing at heating. In order to minimize these negative factors, such QWIPs are usually operating at temperatures not more than $77 \mathrm{~K}$.

In anisotropic QWIPs $[10,11]$ of near-IR range, the outer electric field is not used because in nano layers of wurtzite structure the essential inner fields of spontaneous and piezoelectric polarization appear, forming the triangular shape of potential wells and barriers. Though such QWIPs are functioning both at low and room temperatures, but due to the known difficulties in growth of multi-layered wurtzite superlattices and essential dependence of operating parameters on temperature, their effective work still remains low.

The basic active part of typical QCD [12] consists of equal cascades, each is composed of two parts with different functional purpose: active region and extractor. In active region, an electron, absorbing photon, transits from the ground into the excited level, from which, radiating optical phonons, it tunnels 
through the extractor into the ground state of the next cascade. In QCDs, on the contrary to QWIPs, the dark and other noises are almost absent, that makes these devices useful for the spectroscopic measurements, IR imaging, space applications, etc.

Modern QCDs are operating in a wide range of frequencies: from IR till terahertz. QCD of midand far-IR range $[13,14]$ are composed of isotropic arsenide semiconductors (GaAs, AlAs, InGaAs, InAlAs, etc). For the QCDs of near-IR range $[15,16]$ the broadband anisotropic semiconductors (GaN, AlN, AlGaN, InGaN, etc), forming the deep $(\sim 2 \mathrm{eV})$ quantum wells, are used.

However, the majority of QCDs are characterized by the narrow absorption bands, due to which they cannot be used in the devices which detect IR radiation in wide spectral range. In the refs. [17,18] QCDs of mid- and far-IR range with wide absorption bands were observed. The proposed design of cascades allowed to obtain the significant spectral width but the complicated design of cascades didn't provide the effective phonon-assisted tunneling of electrons.

In this paper, we propose the geometrical design of compact cascade for QCD operating in far-IR range. Its extractor is optimized in order to provide the resonant phonon-assisted tunneling of electrons through the phonon ladder. Analyzing the energy spectrum and oscillator strengths of quantum transitions, we revealed the mechanism of broadening of absorption band, formed by two transitions (with close intensity) between electron states in two-well active region.

\section{Analytical calculation of electron energy spectrum and wave functions in QCD cas- cade}

The separate cascade of QCD (Fig. 1), being the multilayered semiconductor nano heterostructure, with fixed geometrical sizes of wells and barriers in outer mediumbarrier is studied. $O z$ axis of Cartesian coordinate system is normal to the interfaces between structure layers. An electron energy spectrum and wave functions are obtained using the model of rectangular potentials

$$
U(z)= \begin{cases}0, & j=1,3,5, \ldots, N \\ U, & j=0,2,4, \ldots, N+1\end{cases}
$$

and effective mass approximation, taking into account its position-dependence and non-parabolic form of conduction band [19]

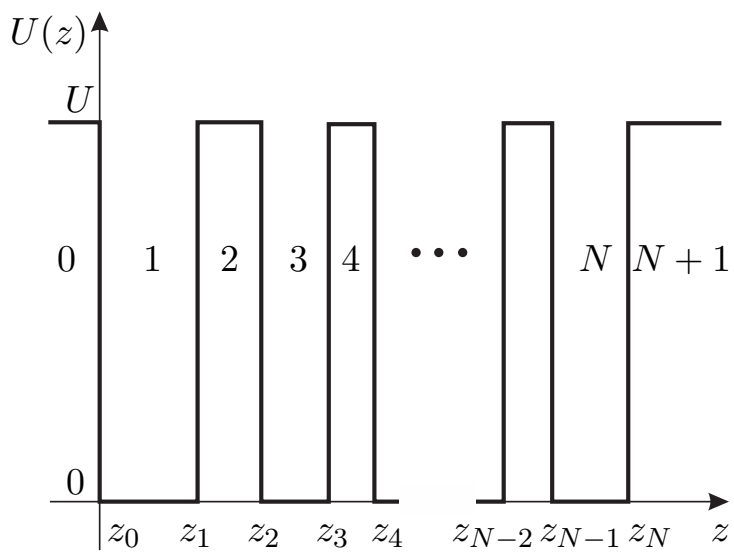

Fig. 1. Geometrical and potential energy scheme of multi-layered heterostructure.

$$
m(E, z)= \begin{cases}m_{w}(E)=m_{w}\left(1+\frac{E}{E_{g w}}\right), & j=1,3,5, \ldots, N \\ m_{b}(E)=m_{b}\left(1-\frac{U-E}{E_{g b}}\right), & j=0,2,4 \ldots, N+1\end{cases}
$$

here $N$ is a number of layers, $U$ is the heights of barriers, $m_{w}, m_{b}$ are the electron effective masses (without non-parabolicity), $E_{g w}, E_{g b}$ are the energy gaps for the bulk crystals of wells and barriers, $E$ is the electron energy.

For the successful QCD operation the electronic current should be normal to the interfaces between the layers, since, further we observe the one-dimensional electronic current along $z$ axis. The electron energies $\left(E_{n}\right)$ and wave functions $\left(\Psi_{n}(z)\right)$ in stationary states $(n)$ are obtained from Schrodinger equation in the form proposed by BenDaniel-Duke [20]

$$
\left[-\frac{\hbar^{2}}{2} \frac{d}{d z} \frac{1}{m\left(E_{n}, z\right)} \frac{d}{d z}+U(z)\right] \Psi_{n}(z)=E_{n} \Psi_{n}(z) .
$$


Its solutions are well known [21,22]:

$$
\Psi_{n}(z)=\sum_{j=0}^{N+1} \Psi_{n}^{(j)}(z) \sigma\left(z-z_{j}\right)
$$

where

$$
\begin{gathered}
\Psi_{n}^{(j)}(z)= \begin{cases}A_{n}^{(j)} e^{\chi_{n} z}+B_{n}^{(j)} e^{-\chi_{n} z}, & j=0,2, \ldots, N+1, \\
A_{n}^{(j)} \cos k_{n} z+B_{n}^{(j)} \sin k_{n} z, & j=1,3, \ldots, N,\end{cases} \\
\sigma\left(z-z_{j}\right)=\theta\left(z-z_{j-1}\right)-\theta\left(z-z_{j}\right), \\
k_{n}=\sqrt{\frac{2 m_{w}\left(E_{n}\right) E_{n}}{\hbar^{2}}}, \quad \chi_{n}=\sqrt{\frac{2 m_{b}\left(E_{n}\right)\left(U-E_{n}\right)}{\hbar^{2}}},
\end{gathered}
$$

$\theta(z)$ is the Heaviside step function, $z_{-1}=-\infty, z_{N+1}=+\infty$.

According to the quantum mechanics [23], the condition of wave function and its density of current continuity at all heterostructure interfaces

$$
\Psi_{n}^{(j)}\left(z_{j}\right)=\Psi_{n}^{(j+1)}\left(z_{j}\right),\left.\quad \frac{d \Psi_{n}^{(j)}(z)}{d z}\right|_{z=z_{j}}=\left.\frac{d \Psi_{n}^{(j+1)}(z)}{d z}\right|_{z=z_{j}}, \quad(j=0, \ldots, N),
$$

finite wave function should at $z= \pm \infty$ and normality condition

$$
\int_{-\infty}^{+\infty} \Psi_{n^{\prime}}^{*}(z) \Psi_{n}(z) d z=\delta_{n n^{\prime}}
$$

fix energy spectrum $\left(E_{n}\right)$ and coefficients $\left(A_{n}^{(j)}, B_{n}^{(j)}\right)$ for wave function $\left(\Psi_{n}(z)\right)$, which are calculated using the computer simulation.

The obtained energies and wave functions give opportunity to study the intensities of quantum transitions between the electron states in QCD cascade, within calculation of oscillator strengths of transitions between the states with the energies $E_{n}$ and $E_{n^{\prime}}$

$$
f_{n n^{\prime}}=\frac{2\left(E_{n}-E_{n^{\prime}}\right)}{\hbar^{2}} \sum_{j=0}^{N+1} \bar{m}_{j}\left|\int_{z_{j-1}}^{z_{j}} \Psi_{n^{\prime}}^{(j) *}(z) z \Psi_{n}^{(j)}(z) d z\right|^{2},
$$

where $\bar{m}_{j}$ is the average effective mass of electron in the states $n$ and $n^{\prime}$ in layer $j$.

\section{Optimal geometrical design of cascade of QCD operating in far-IR range}

It is well known $[1,2]$, that the main idea of QCD successful functioning lays in the mechanism of socalled "phonon ladder", produced by the equidistant electron energy levels in extractor. The distances between these levels resonate with the energy of optical phonon $\left(\Omega_{L 0}\right)$. This can be provided by the proper choice of the sizes of wells and barriers and their order in the extractor. If geometrical design is optimal, the electron from the upper level of active region of previous cascade, tunneling through the extractor within the sequential one-phonon quantum transitions (over the phonon ladder) will exactly get to the ground level of active region of the next cascade. The same scheme, according to the idea of [24], was realized in experimental QCD of far-IR range. It is to be mentioned that in isotropic and anisotropic QCDs $[3,6,15,16]$, the phonon ladder with missed or not optimal steps of energies is usually used. Thus, the effectiveness of such devices is rather low.

In order to study the spectral characteristics of QCD [24], using the theory developed in the previous Section, we calculated the energy spectrum $\left(E_{n}\right)$, differences between the energies of neighbour states $\left(\Delta E_{n n-1}=E_{n}-E_{n-1}\right)$, oscillator strengths of quantum transitions $\left(f_{1 n}\right)$ of electron from the ground 
$(n=1)$ into the excited states $(n>1)$ and its wave functions $\left(\Psi_{n}(z)\right)$ in separate cascade. Physical and geometrical parameters of QCD cascade [24] with GaAs wells and $\mathrm{Al}_{0.33} \mathrm{Ga}_{0.67}$ As barriers: $a_{1}=6.8 \mathrm{~nm}$, $a_{2}=2 \mathrm{~nm}, a_{3}=2.3 \mathrm{~nm}, a_{4}=2.8 \mathrm{~nm}, a_{5}=3.4 \mathrm{~nm}, a_{6}=3.8 \mathrm{~nm}, a_{7}=4.8 \mathrm{~nm}$ are the widths of the wells, respectively; $b_{1}=5.65 \mathrm{~nm}, b_{2}=3.955 \mathrm{~nm}, b_{3}=3.1 \mathrm{~nm}, b_{4}=3.1 \mathrm{~nm}, b_{5}=3.1 \mathrm{~nm}, b_{6}=3.1 \mathrm{~nm}$ are the thickness of the barriers; $U=276 \mathrm{meV}$ is the height for all barriers; $E_{g}^{\mathrm{GaAs}}=1520 \mathrm{meV}$, $E_{g}^{\mathrm{AlGaAs}}=1885 \mathrm{meV}$ are the energy gaps, $m_{w}=0.067 m_{e}, m_{b}=0.095 m_{e}$ are the effective masses with $m_{e}$ - the electron mass in vacuum.

The results of calculation for $E_{n}, \Delta E_{n n-1}$ and $f_{1 n}$ are presented in Table 1.

Table 1. The electron energies $\left(E_{n}\right)$, differences between the energies of neighbour states $\left(\Delta E_{n n-1}\right)$ and oscillator strengths of its quantum transitions $\left(f_{1 n}\right)$ from the ground into excited states in QCD [24],

\begin{tabular}{|c|c|c|c|}
\hline$n$ & $E_{n}, \mathrm{meV}$ & $\triangle E_{n n-1}, \mathrm{meV}$ & $f_{1 n}$ \\
\hline 1 & 54.5 & - & - \\
\hline 2 & 81.4 & 26.9 & 0.24 \\
\hline 3 & 103.2 & 21.8 & 0.02 \\
\hline 4 & 120.4 & 17.2 & $0.36 \cdot 10^{-2}$ \\
\hline 5 & 140.9 & 20.5 & $0.53 \cdot 10^{-4}$ \\
\hline 6 & 166.9 & 26.1 & 0.02 \\
\hline 7 & 187.9 & 20.9 & 0.27 \\
\hline 8 & 196.7 & 8.8 & 0.57 \\
\hline
\end{tabular}

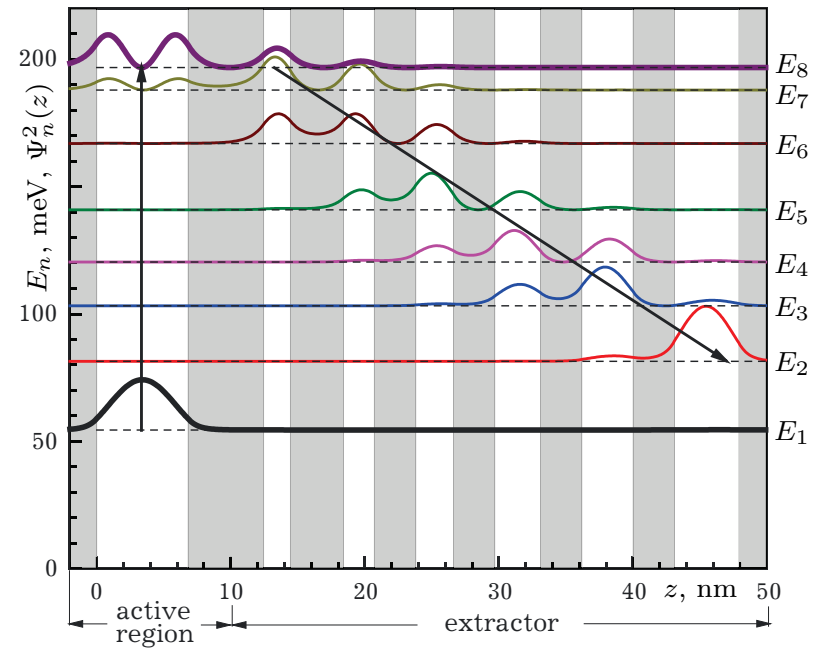

Fig. 2. Probability distributions of electron location in the states $n=1 \div 8$ in separate cascade of QCD [24].

In Fig. 2, the probabilities $\left(\Psi_{n}^{2}(z)\right)$ of electron location in QCD cascade, normalized with respect to the energies $\left(E_{n}\right)$, are presented. Figure shows that in the states $n=1$ and $n=8$ the electron is mainly localized in single-well active region of the cascade. Quantum transition between the states with the energies $E_{1}$ and $E_{8}$ (Table 1 ) is provided by the absorption of photon energy $\Delta E_{81}=142.2 \mathrm{meV}$, that agrees with the experimental magnitude $\Delta E_{\exp }=144 \mathrm{meV}$.

In the states $n=2 \div 7$, the electron is sequentially localized in extractor wells in such a way that the energy levels $\left(E_{2}, \ldots, E_{7}\right)$ form a non-optimized phonon ladder. We should note that the distances $\left(\Delta E_{n n-1}\right)$ between the steps of the ladder are much smaller than optical phonon energy $\left(\Omega_{L 0}^{\mathrm{GaAs}}=36.2 \mathrm{meV}\right)$, since, the phonon-assisted tunneling of electrons through the extractor is nonresonant. Therefore, the effectiveness of experimental QCD [24] functioning is rather low.

Let us optimize geometrical design of the cascade in order to provide QCD successful operation in demanded spectral range with resonant phonon-assisted tunneling of electrons. From physical considerations it is clear that the energy $\left(\Delta E_{n 1}\right)$ of the transition between the levels of active region in cascade with optimal phonon ladder must be multiple of the phonon energy $\left(\Omega_{L 0}^{\mathrm{GaAs}}\right)$ and each its step is to be formed by only one well of the extractor. Since, the number of potential wells in extractor is determined by the equality $p=\frac{\Delta E_{n 1}}{\Omega_{L 0}^{G a A s}}-1$, where $p$ is positive integer. As a result, fixing the detected energy $\left(\Delta E_{n 1}\right)$ and phonon energy $\left(\Omega_{L 0}^{\mathrm{GaAs}}\right)$, one can define the optimal number of potential wells in the extractor, which form the ladder with the steps resonating with energy of optical phonon. The numeric calculations prove that if in QCD under study $\Delta E_{n 1}=144 \mathrm{meV}$ and $\Omega_{L 0}^{\mathrm{GaAs}}=36.2 \mathrm{meV}$, then, the resonant phonon ladder is formed by three-well $(p=3)$ extractor with the following geometrical parameters: $2.3 \mathrm{~nm}, 3.0 \mathrm{~nm}$ and $4.2 \mathrm{~nm}$ are the widths of the wells, $3.1 \mathrm{~nm}$ and $3.1 \mathrm{~nm}$ are the thicknesses of the barriers.

The QCDs are usually applied as main elements of modern IR sensors with wide absorption band. Thus, further, we shall optimize the geometrical design of cascades active region in order to provide QCD operation in wide IR range, which covers the energy $144 \mathrm{meV}$. It is well known [18, 24], that one of the ways to broaden the QCD absorption band is to use two-well active region with close energy levels. 

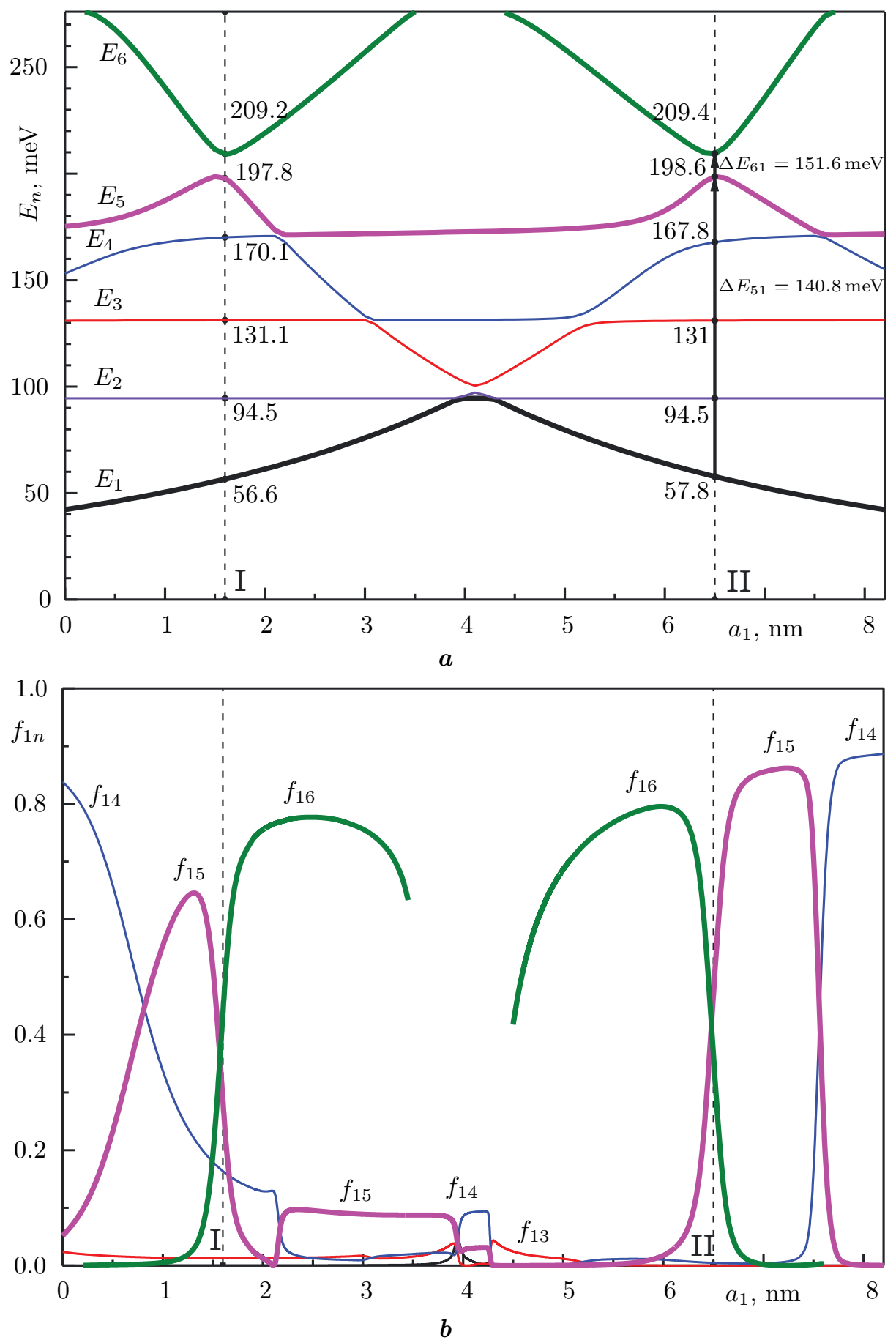

Fig. 3. Influence of the prestress level on the amplitude-frequency $(\boldsymbol{a})$ and temperature-frequency $(\boldsymbol{b})$ curves for the center point of the square plate.

So, let us observe the active region with two wells $\left(a_{1}, a_{2}\right)$, separated by the barrier $\left(b_{1}=5.65 \mathrm{~nm}\right)$. The width of the first well $\left(a_{1}=6.8 \mathrm{~nm}\right)$ is the same as in experimental QCD [24] while the width of the second well $\left(a_{2}=1.4 \mathrm{~nm}\right)$ is chosen such that the formed in it single energy level should be close to the upper level in the first well. QCD with such construction of active region will operate within the transitions from the ground level into two close upper levels of active region with the width of absorption band equal to the difference between the energies of two transitions. It is to be mentioned that the increasing number of potential wells in active region weakly influence on the energy levels of phonon ladder. 
In order to establish uniquely optimal widths of wells in active region, the electron energies $\left(E_{n}\right)$ and oscillator strengths of quantum transitions $\left(f_{1 n}\right)$ from the ground state into the excited states in cascade with three-well extractor were studied as functions of width of the first well $\left(a_{1}\right)$ at the constant sum width of both wells: $a_{1}+a_{2}=8.2 \mathrm{~nm}$. The results of numeric calculations for $E_{n}\left(a_{1}\right)$ and $f_{1 n}\left(a_{1}\right)$ functions are shown in Fig. 3.

From Fig. $3 a$ it is clear that $E_{n}\left(a_{1}\right)$ are non-monotonous functions with typical anti-crossing effect [22]. The character of these dependencies allow to reveal the regions of electron localization. If $E_{n}$ decays when $a_{1}$ increases, the electron in the state $n$ is localized in the first potential well $\left(a_{1}\right)$ of active region. If $E_{n}$ increases when $a_{1}$ increases, the electron is localized in the second well $\left(a_{2}=\left(8.2-a_{1}\right) \mathrm{nm}\right)$ and if $E_{n}\left(a_{1}\right)$ horizontal - it is located in the extractor.

Also, Fig. $3 a$ shows two geometrical configurations of active region (I: $a_{1}^{\mathrm{I}}=1.6 \mathrm{~nm}, a_{2}^{\mathrm{I}}=6.6 \mathrm{~nm}$ and II: $\left.a_{1}^{\mathrm{II}}=6.5 \mathrm{~nm}, a_{2}^{\mathrm{II}}=1.7 \mathrm{~nm}\right)$, where two quantum transitions are realized $(|1\rangle \rightarrow|5\rangle$ and $|1\rangle \rightarrow|6\rangle)$ from the ground state with the energy $\left(E_{1}\right)$ into two excited states with close energies $\left(E_{5}, E_{6}\right)$, which are anti-crossing [22]. The energies of transitions in both configurations are close (I: $\Delta E_{51}^{\mathrm{I}}=141.2 \mathrm{meV}$, $\Delta E_{61}^{\mathrm{I}}=152.6 \mathrm{meV}$ and II: $\left.\Delta E_{51}^{\mathrm{II}}=140.8 \mathrm{meV}, \Delta E_{61}^{\mathrm{II}}=151.6 \mathrm{meV}\right)$.

It is clear that for the successful detecting in needed spectral range, the oscillator strengths $f_{15}$ and $f_{16}$ must be close and much bigger than that of the other transitions $\left(f_{1 n \neq 5,6}\right)$. Fig. $3 b$ proves that this condition is fulfilled only for II configuration, where the oscillator strengths $f_{15}^{\mathrm{II}}=0.28, f_{16}^{\mathrm{II}}=0.44$ are much bigger than the others $\left(f_{15}, f_{16} \gg f_{1 n \neq 5,6}\right)$. In I configuration this condition is not fulfilled because $f_{15}^{I}=0.47, f_{16}^{\mathrm{I}}=0.36$ are commensurate with $f_{14}^{\mathrm{I}}=0.16$.

As a result, the effective functioning of QCD in far-IR range is possible only with an one optimal configuration of active region $\left(a_{1}=6.5 \mathrm{~nm}, a_{2}=1.7 \mathrm{~nm}\right.$ are the widths of the wells) and the spectral width of absorption band is defined by the difference $\Delta E_{61}-\Delta E_{51}$. Fig. $3 a$ shows that a slight deviation from $a_{1}^{\mathrm{II}}$ value gives rise the changes of $\Delta E_{51}, \Delta E_{61}$ magnitudes and, since, to the change of absorption band width.

To evaluate the optimal sizes of cascade barriers, the electron energies $\left(E_{n}\right)$ and oscillator strengths $\left(f_{1 n}\right)$ were calculated as functions of barriers thicknesses $\left(b_{1}, b_{2}, b_{3}, b_{4}\right)$ at the fixed wells widths: $a_{1}=6.5 \mathrm{~nm}, a_{2}=1.7 \mathrm{~nm}, a_{3}=2.3 \mathrm{~nm}, a_{4}=3.0 \mathrm{~nm}, a_{5}=4.2 \mathrm{~nm}$. The results are presented in Fig. 4 . Increasing thickness of the first barrier $\left(b_{1}\right)$ at the fixed sizes of the other barriers, shown in Fig. $4 a$, gives rise to the narrowing of the absorption band $\left(\Delta E_{61}-\Delta E_{51}\right)$, caused by the smaller distance between energy levels $\left(E_{5}, E_{6}\right)$ in anti-crossing but almost does not effect on the energy levels $\left(E_{2}, E_{3}\right.$, $E_{4}$ ) of phonon ladder. It makes possible to tune spectral width of the band by proper choose of $b_{1}$. From Fig. $4 b$ it is clear that the minimal thickness of the first potential barrier $\left(b_{1}^{\min } \approx 5 \mathrm{~nm}\right)$ is fixed by the condition $f_{15}, f_{16} \gg f_{1 n \neq 5,6}$.

Fig. $4 d$ proves that the condition $f_{15} \approx f_{16}$ is provided by choose of the second barrier thickness $\left(b_{2}=4.2 \mathrm{~nm}\right)$. The thicknesses of the third barrier $\left(b_{3}\right)$, taken from the interval $3 \mathrm{~nm} \leqslant b_{3} \leqslant 4 \mathrm{~nm}$ (Fig. $4 e, f)$ and that of the forth barrier $\left(b_{4}\right)$ from $0.5 \mathrm{~nm} \leqslant b_{4} \leqslant 4 \mathrm{~nm}$ (Fig. $4 g, h$ ), where the condition $f_{15}, f_{16} \gg f_{1 n \neq 5,6}$ is fulfilled, finally optimize the position of energy levels $\left(E_{2}, E_{3}, E_{4}\right)$ in phonon ladder.

Finally, presented analysis of electron energies and oscillator strengths of quantum transitions determines the design of compact optimal QCD, operating in far-IR range, with following geometrical parameters: $a_{1}=6.5 \mathrm{~nm}, a_{2}=1.7 \mathrm{~nm}, a_{3}=2.3 \mathrm{~nm}, a_{4}=3.0 \mathrm{~nm}, a_{5}=4.2 \mathrm{~nm}, b_{1}=5.65 \mathrm{~nm}$, $b_{2}=3.955 \mathrm{~nm}, b_{3}=3.1 \mathrm{~nm}, b_{4}=3.1 \mathrm{~nm}$.

In the Table 2 and Fig. 5 the electron energies $\left(E_{n}\right)$, differences of energies $\left(\Delta E_{n n-1}\right)$, oscillator strengths of quantum transitions $\left(f_{1 n}\right)$ and probability distributions of its location $\left(\Psi_{n}^{2}(z)\right)$ in optimized cascade of QCD with two-well active region are presented. Table 2 shows two quantum transitions with almost the same intensities $\left(f_{15}=0.42, f_{16}=0.41\right)$ and transition energies $\left(\Delta E_{51}=140 \mathrm{meV}, \Delta E_{61}=\right.$ $150.9 \mathrm{meV}$ ). The intensities of all other transitions are much smaller than $f_{15}$ and $f_{16}$. Extractor energy levels $E_{2}, E_{3}, E_{4}$, Fig. 5, form the phonon ladder with resonant steps, relatively to the optical phonon energy $\left(\Omega_{L 0}^{\mathrm{GaAs}}=36.2 \mathrm{meV}\right)$. The proposed geometrical design of compact cascade will provide the 

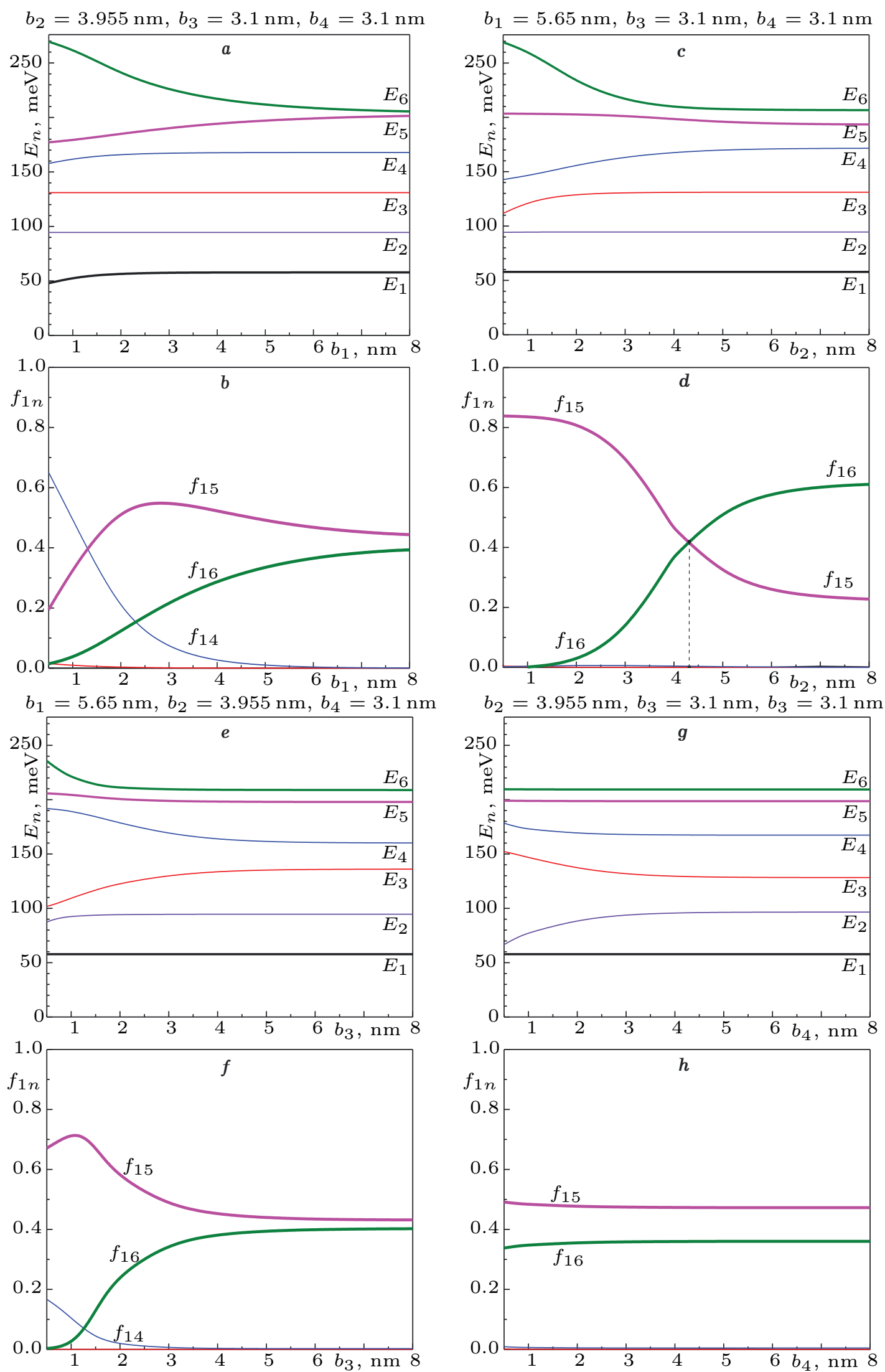

Fig. 4. Electron energies $\left(E_{n}\right)$ and oscillator strengths of quantum transitions $\left(f_{1 n}\right)$ as functions of barriers thicknesses $b_{i}(i=1-4)$ in QCD cascade. 
successful functioning of broadband QCD in far-IR range with resonant phonon-assisted tunneling of electrons through the phonon ladder.

Table 2. Electron energies $\left(E_{n}\right)$, differences between the energies of neighbour states $\left(\Delta E_{n n-1}\right)$ and oscillator strengths $\left(f_{1 n}\right)$ of quantum transitions from the ground state into excited ones in optimal cascade of QCD.

\begin{tabular}{|c|c|c|c|}
\hline$n$ & $E_{n}, \mathrm{meV}$ & $\triangle E_{n n-1}, \mathrm{meV}$ & $f_{1 n}$ \\
\hline 1 & 57.8 & - & - \\
\hline 2 & 94.5 & 36.7 & $1.94 \cdot 10^{-7}$ \\
\hline 3 & 131.1 & 36.6 & $0.43 \cdot 10^{-4}$ \\
\hline 4 & 168.5 & 37.5 & $0.41 \cdot 10^{-2}$ \\
\hline 5 & 197.8 & 29.3 & 0.42 \\
\hline 6 & 208.7 & 10.9 & 0.41 \\
\hline
\end{tabular}

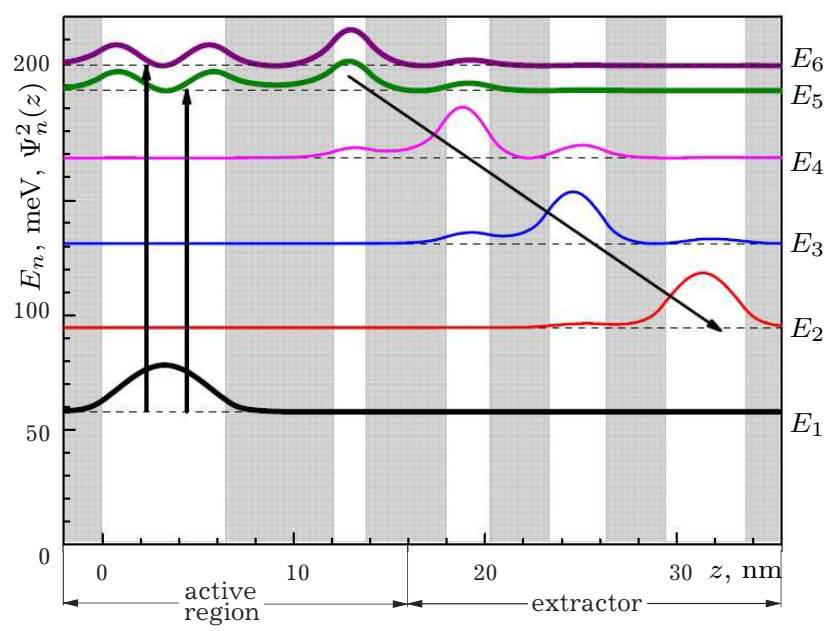

Fig. 5. Probability distributions of electron location in optimal cascade of QCD.

\section{Results and conclusions}

The theory of electron energy spectrum and oscillator strengths of quantum transitions in multilayered nano heterostructure, being the cascade of QCD operating in far-IR range, is developed. The geometrical design of cascade with two-well active region and extractor with optimal phonon ladder, which produces the resonant phonon-assisted tunneling of electrons, providing the effective operation of broadband QCD, is proposed.

It is shown that the active region with two potential wells of different widths, where two quantum transitions with almost the same intensities, accompanied by absorption of photons with close but different frequencies, occur, broadens the spectral absorption band of QCD. Its width essentially depends on the thickness of the potential barrier between the wells of the active region, decreasing due to the smaller distance between the energy levels in anti-crossing.

The further optimization of QCD geometrical design needs taking into account the effect of interaction with phonons on its spectral characteristics, that would be done in the future.

[1] Lei W., Jagadish C. Lasers and photodetectors for mid-infrared $2-3 \mu$ m applications. J. Appl. Phys. 104 (9), 091101 (2008).

[2] Tournie E., Cerutti L. Mid-infrared Optoelectronics. Woodhead Publishing (2019).

[3] Beeler M., Trichas E., Monroy E. III-nitride semiconductors for intersubband optoelectronics: a review. Semicond. Sci. Technol. 28 (7), 074022 (2013).

[4] Gunapala S., Bandara S., Liu J., Mumolo J., Rafol S., Ting D. Z., Soibel A., Hill C. Quantum Well Infrared Photodetector Technology and Applications. IEEE J. Sel. Top. Quantum Electron. 20 (6), 3802312 (2014).

[5] Levine B., Choi K., Bethea C., Walker J., Malik R. New 10 $\mu \mathrm{m}$ infrared detector using intersubband absorption in resonant tunneling GaAIAs superlattices. Appl. Phys. Lett. 50 (16), 1092-1094, (1987).

[6] Gendron L., Carras M., Huynh A., Ortiz V. Quantum cascade photodetector. Appl. Phys. Lett. 85 (4), 2824-2826 (2004).

[7] Schneider H., Liu H. Quantum Well Infrared Photodetectors. Physics and Applications. (2006).

[8] Gueriaux V., Nedelcu A., Bois Ph. Double barrier strained quantum well infrared photodetectors for the $3-5 \mu \mathrm{m}$ atmospheric window. J. Appl. Phys. 105 (11), 114515 (2009).

[9] Kaya Ya., Ravikumar A., Chen G., Tamargo M. C., Shen A., Gmachl C. Two-band ZnCdSe/ZnCdMgSe quantum well infrared photodetector. AIP Advances. 8 (7), 075105 (2018). 
[10] Hofstetter D., Schad S., Wu H., Schaff W., Eastman L. GaN/AlN-based quantum-well infrared photodetector for $1.55 \mu \mathrm{m}$. Appl. Phys. Lett. 83 (3), 572-574 (2003).

[11] Mensz P., Dror B., Ajay A., Bougerol C., Monroy E., Orenstein M., Bahir G. Design and implementation of boundto-quasibound GaN/AlGaN photovoltaic quantum well infrared photodetectors operating in the short wavelength infrared range at room temperature. J. Appl. Phys. 125 (17), 174505 (2019).

[12] Giorgetta F., Baumann E., GrafM., Yang Q., Manz C., Kohler K., Beere H. E., Ritchie D. A., Linfield E., Davies A. G., Fedoryshyn Yu., Jackel H., Fischer M., Faist J., Hofstetter D. Quantum Cascade Detectors. Journal of quantum electronics. 45 (8), 1039-1052 (2009).

[13] Reininger P., Zederbauer T., Schwarz B., Detz H., MacFarland D., Andrews A. M., Schrenk W., Strasser G. InAs/AlAsSb based quantum cascade detector. Appl. Phys. Lett. 107 (8), 081107 (2015).

[14] Liu J., Zhou Y., Zhai S., Liu F., Liu S., Zhang J., Zhuo N., Wang L., Wang Z. High-frequency very long wave infrared quantum cascade detectors. Semicond. Sci. Technol. 33 (12), 125016 (2018).

[15] Sakr S., GiraudE., Dussaigne A., Tchernycheva M., Grandjean N., Julien F.H. Two-color GaN/AlGaN quantum cascade detector at short infrared wavelengths of 1 and $1.7 \mu \mathrm{m}$. Appl. Phys. Lett. 100 (18), 181103 (2012).

[16] Sakr S., Crozat P., Gacemi D., Kotsar Y., Pesach A., Quach P., Isac N., Tchernycheva M., Vivien L., Bahir G., Monroy E., Julien F. H. GaN/AlGaN waveguide quantum cascade photodetectors at $1.55 \mathrm{~m}$ with enhanced responsivity and $40 \mathrm{GHz}$ frequency bandwidth. Appl. Phys. Lett. 102 (1), 011135 (2013).

[17] Hofstetter D., Giorgetta F., Baumann E., Yang Q., Manz C., Köhler K. Midinfrared quantum cascade detector with a spectrally broad response. Appl. Phys. Lett. 93 (22), 221106 (2008).

[18] Zhou X., Li N., LuW. Progress in quantum well and quantum cascade infrared photodetectors in SITP. Chin. Phys. B. 28 (2), 027801 (2019).

[19] Nelson D., Miller R., Kleinman D. Band nonparabolicity effects in semiconductor quantum wells. Phys. Rev. B. 35 (14), 7770-7773 (1987).

[20] BenDaniel D., Duke C. Space-Charge Effects on Electron Tunneling. Phys. Rev. 152 (2), 683-692 (1966).

[21] Harrison P., Valavanis A. Quantum wells, wires and dots: theoretical and computational physics of semiconductor nanostructures. Wiley, West Sussex, United Kingdom (2016).

[22] Tkach M., Seti Ju., Voitsekhivska O. Spectrum of electron in quantum well within the linearly-dependent effective mass model with the exact solution. Superlattice Microst. 109, 905-914 (2017).

[23] Davydov A. Theory of solids. Nauka, Moscow (1976).

[24] Li L., Zhou X., Tang Z., Zhou Y.,Zheng Y., Li N., Chen P., Li Z., Lu W. Long wavelength infrared quantum cascade detector with a broadband response. J. Phys. D: Appl. Phys. 51 (37), 37LTO1 (2018).

[25] Tkach M., SetiJu., Grynyshyn Y., Voitsekhivska O. Dynamic Conductivity of Electrons and Electron Phonon Interaction in Open Three-Well Nanostructures. Acta Phys. Pol. A. 128 (3), 343-352 (2015). 


\title{
Моделювання оптимізованого каскаду квантового каскадного детектора далекого інфрачервоного діапазону
}

\author{
Сеті Ю. О., Ткач М. В., Верешко Є. Ю., Войцехівська О. М. \\ Чернівецвкий начіональний університет ім. Ю. Федъковича, \\ вул. Кочюбинського, 2, 58012, Чернівиі, Украӥна
}

\begin{abstract}
На основі розвиненої у моделі координато-залежної ефективної маси та прямокутних потенціалів теорії енергетичного спектра електрона та сил осциляторів міжпідзонних квантових переходів запропоновано геометричний дизайн компактного каскаду квантового каскадного детектора далекого ІЧ діапазону з двоямною активною зоною. Екстрактор каскаду оптимізовано так, щоб енергетичні щаблі його фононної драбинки резонували з енергією оптичного фонона, що забезпечує ефективне фононсупровідне тунелювання електронів між активними зонами каскадів наноприладу. Встановлено, що зменшення товщини бар'єра між ямами активної зони внаслідок збільшення відстані між рівнями в антикросингу приводить до розширення смуги поглинання детектора.
\end{abstract}

Ключові слова: наносистема, квантовий каскадний детектор, енергетичний спектр, фонон-супровідне тунелювання. 